\title{
The University of British Columbia First Nations Forestry Program
}

\author{
Madeleine MacIvor ${ }^{1}$
}

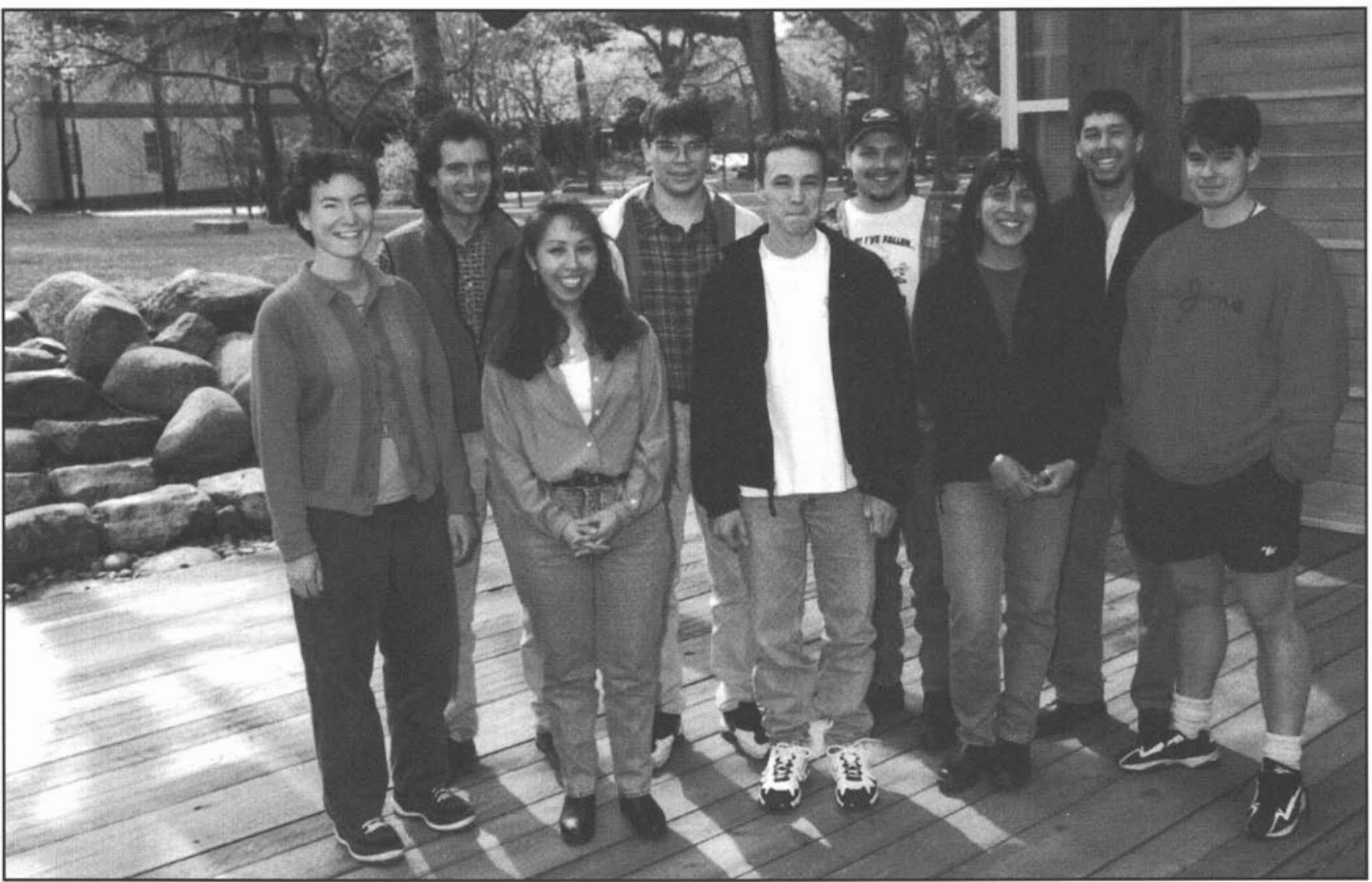

Back row, left to right: Carl Mashon (Cree) Stephen Watkinson (Tsimshian); Guy Wright (Kwakwaka'wakw); Lennard Joe (Nlak'pamux). Front row, left to right: Rebecca McKay (Cree); Angeline Nyce (Nisga'a), Chris Anderson (Nuu-chah-nulth); Andrea Lyall (Kwakwaka'wakw); Matt Wealick (Sto:lo).

The University of British Columbia (UBC) Faculty of Forestry established a program to encourage and support Aboriginal students interested in pursuing forestry education at the university. The UBC First Nations Forestry Program has played an important role in the Faculty. In 1994, there were only two First Nations students enrolled in the Faculty of Forestry - today there are fifteen. This enrollment increase reflects the Faculty's commitment to address the need for professional forestry education amongst First Nations by:

- increasing the participation of First Nations students in the Faculty;

- providing support services for First Nations students;

- incorporating First Nations perspectives and issues within the forestry curriculum, and;

- creating an awareness within the university and the wider

${ }^{1}$ Coordinator - First Nations Forestry Program, Faculty of Forestry, UBC. community about First Nations perspectives and issues in forestry.

In addition to ongoing promotion and recruitment, the Faculty is raising awareness of forestry opportunities for First Nations through two First Nations youth programs: the Summer Science Program, and the Synala Honours Program. A strong relationship also exists between the Faculty and the First Nations Professional Sciences Access Program (FNPSAP), an upgrading program for First Nations students who are interested in professional careers in the sciences. Two current First Nations forestry students gained entrance to the Faculty through this program, and this year there are five students in the FNPSAP who are intending to enter the forestry program.

Recognizing the significant role that Aboriginal post-secondary institutions play in the education of First Nations members, the Faculty has an articulation agreement with the Nicola Valley Institute of Technology (NVIT) in Merritt, $\mathrm{BC}$, which enables graduates from NVIT's Natural Resources 
Technology Program to apply for admission into the three-year version of the Faculty's professional forestry programs.

Support services are an important part of the Faculty's initiatives. Support through the Faculty's Coordinator of Student Services, and Coordinator of the Faculty's FNFP are enhanced by the Faculty's close relationship with the First Nations House of Learning, a "home away from home" for Aboriginal students on campus.

The needs of First Nations students go beyond access and support issues, to include issues related to the curriculum itself. The Faculty now offers the third year course, "Perspectives on First Nations and Forest Lands," and has developed a strategy to incorporate First Nations content throughout the existing curricula, for the benefit of all forestry students. As Dean Clark Binkley states, "Not only is there a great need to have First Nations people enter into the forestry and natural resources sectors as professionals, but it is equally critical that the non-native forestry and conservation students learn more about First Nations perspectives and Aboriginal rights, culture and land ethics."
In contemplating curriculum initiatives, the Faculty reached out to the international community. In cooperation with the National Aboriginal Forestry Association and the First Nations House of Learning, the Faculty of Forestry hosted the "Indigenous Perspectives in Forestry Education" workshop, in June of 1997. This gathering provided the opportunity to some 150 participants from around the world to reflect upon the relationship between culture, curriculum and forestry. Details of the conference can be found in the September/October 1997 issue of The Forestry Chronicle and on the Internet at: http://www.forestry.ubc.ca/firstnat/workshop.html.

Thanks to funding from the BC Ministry of Forests, the Faculty is currently working with the British Columbia Forestry Continuing Studies Network on a First Nations and forest lands workshop for forestry practitioners. Through these and other initiatives, the UBC Faculty of Forestry is striving to create meaningful change, as it responds to the needs of First Nations, and the changing context of forestry in British Columbia. 